\section{THE EUROPEAN SOCIETY FOR COMPUTING AND TECHNOLOGY IN ANAESTHESIA AND INTENSIVE CARE (ESCTAIC): A SPECIAL ISSUE OF FULL PAPERS (BERLIN MEETING 2009) AND CONFERENCE ABSTRACTS (AMSTERDAM MEETING 2010)}

Stephen Edward Rees, PhD
From the Center for Model-Based Medical Decision Support Systems, Aalborg University, Niels Jernes vej 14, 4-313, DK-9220 Aalborg East, Denmark.

Address correspondence to S. E. Rees, Center for Model-Based Medical Decision Support Systems, Aalborg University, Niels Jernes vej 14, 4-313, DK-9220 Aalborg East, Denmark.

E-mail: sr@hst.aau.dk
Rees SE. The European Society for Computing and Technology in Anaesthesia and Intensive Care (ESCTAIC): a special issue of full papers (Berlin meeting 2009) and conference abstracts (Amsterdam meeting 2010).

J Clin Monit Comput 2011; 25:1-2

The European Society for Computing and Technology in Anaesthesia and Intensive Care (ESCTAIC) is a forum for communication between the clinical disciplines of anaesthesiology and intensive care medicine, and technical disciplines including engineering and computer science. ESCTAIC organizes annual conferences (www.esctaic.org) and has recently become one of the specialist societies of the European Society of Anaesthesiology.

ESCTAIC has a long standing collaboration with the Journal of Clinical Monitoring and Computing, with the journal regularly publishing abstracts from the societies meetings. As a new initiative, following ESCTAIC's 2009 meeting in Berlin [1], selected authors were requested to write full papers for submission to the journal. This initiative is planned for future ESCTAIC meetings and this issue of the JCMC represents the first ESCTAIC special issue of the journal, including full papers from the Berlin meeting, plus the abstracts of ESCTAIC's 2010 meeting in Amsterdam. Seven full papers were accepted following peer review, for publication for this issue, and these papers represent a good selection of the activities presented at ESCTAIC meetings. All new initiatives take time to mature and unfortunately, three of the papers were mistakenly published in issues proceeding this (Efrati et al. [2], Zenker [3], Wooten [4]).

Efrati and collegues [2] review the current state of activities aimed at preventing ventilator induced pneumonia (VAP). In doing so, they comment on the twofold strategy of improved clinical practice guidelines along with technological developments such as the design of endotracheal tubes to prevent infection. Zenker [3] describes a mathematical approach, applied to the cardiovascular physiology, for combining mechanistic models of physiology with quantitative observations in decision support. The approach is based on probability theory, and Zenker illustrates using simulated clinical scenarios, how parameters describing patients' cardiovascular state can be updated to account for clinical measurements. Hemodynamic monitoring is also an area addressed by Cannesson and collegues [5], in their review of the pulse pressure variation technique. They review the history, the technological and physiological background, and the current state of the art in both the commercial and scientific domains, commenting on the role of the technique in directing fluid management. 
Two great debates have dominated the field of acidbase in the past decades: the first, known as the "Great Trans-Atlantic" debate, contrasted the empirical rules of acid-base interpretation of the 'Boston' school with the quantitative approach based in Copenhagen; the second, has contrasted two quantitative approaches, i.e. that based-on strong ion theory with that based in Copenhagen. Two papers $[4,6]$ illustrate the apparent consistency of these approaches. Matousek and colleagues [6] illustrate that, for plasma, the two quantitative approaches are almost interchangeable; and Wooten [3], illustrates that models can be formulated for both quantitative approaches which, when including blood and interstitial fluid, are similar, and can be used to derive the 'Boston rules'.

Bibian and collegues [7] address the topic of depth of anesthesia monitoring, a subject which has been a focus of ESCTAIC meetings over many years. They compare the performance of three brain function monitors to assess whether their feedback characteristics are linear and time invariant, finding that one of the three monitors fulfilled this requirement. Anesthesia information management systems (AIMS), also a core topic of the society, are addressed in the paper of Ehrenfeld and Rehman [8]. They provide an account of the potential of introducing AIMS and the considerations necessary when: preparing a business case; deciding upon functionality, deciding upon the system and vendor to choose, and implementation issues including ergonomics and user training.

\section{REFERENCES}

1. Marsolek I, Dellermalm A, Krummreich L, Rees SE, Friesdorf W. Selected abstracts presented at the 20th meeting of the European Society for Computing and Technology in Anaesthesia and Intensive Care (ESCTAIC), Berlin, Germany, Technical University, 23-26 September, 2009. J Clin Monit Comput. 2010; 24: 1-33.

2. Efrati S, Deutsch I, Antonelli M, Hockey PM, Rozenblum R, Gurman GM. Ventilator-associated pneumonia: current status and future recommendations. J Clin Monit Comput 2010; 24(2): 161-168.

3. Zenker S. Parallel particle filters for online identification of mechanistic mathematical models of physiology from monitoring data: performance and real-time scalability in simulation scenarios. J Clin Monit Comput 2010; 24(4): 319-333.

4. Wooten EW. The standard strong ion difference, standard total titratable base, their relationship to the Boston compensation rules, the Van Slyke equation for extracellular fluid. J Clin Monit Comput 2010; 24(3): 177-188.

5. Cannesson M, Aboy M, Hofer CK, Rehman M. Pulse pressure variation: where are we today? J Clin Monit Comput. 2011. doi:10.1007/s10877-010-9229-1.

6. Matousek S, Handy J, Rees SE. Acid-base chemistry of plasma: consolidation of the traditional and modern approaches from a mathematical and clinical perspective. J Clin Monit Comput. 2011. doi:10.1007/s10877-010-9250-4.

7. Bibian S, Dumont GA, Zikov T. Dynamic behavior of BIS, M-entropy and neuroSENSE brain function monitors. J Clin Monit Comput. 2011. doi:10.1007/s10877-010-9266-9.

8. Ehrenfeld JM, Rehman MA. Anesthesia information management systems: a review of functionality and installation considerations. J Clin Monit Comput. 2011. doi:10.1007/ s10877-010-9256-y. 